\title{
GENETIC RELATIONSHIP ANALYSIS OF WILD (OLEA CUSPIDATA WALL.) AND CULTIVATED OLIVE (OLEA EUROPAEA L.) GROWING IN AZAD JAMMU AND KASHMIR, PAKISTAN
}

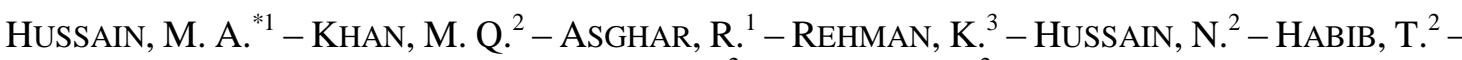 \\ DAR, M. E. U. I. ${ }^{2}-$ SHAHEEN, H. ${ }^{2}$ \\ ${ }^{I}$ Department of Biotechnology, Mirpur University of Science and Technology (MUST) Mirpur- \\ 10250, (AJK), Pakistan \\ ${ }^{2}$ Department of Botany, University of Azad Jammu and Kashmir, Muzaffarabad-13100, \\ Pakistan \\ ${ }^{3}$ Department of Botany, Mirpur University of Science and Technology (MUST), Bhimber \\ Campus, Bhimber Azad Kashmir, Pakistan \\ *Corresponding author \\ e-mail: scholar.altaf@gmail.com \\ (Received $3^{\text {rd }}$ Dec 2016; accepted $22^{\text {nd }}$ Mar 2017)
}

\begin{abstract}
Wild (O. cuspidata) and cultivated olive (O. europaea) grow in northern regions of Pakistan including Azad Jammu and Kashmir are expected to have considerable inter and intra-species genetic variability due to adaptation to the various environmental conditions. The genetic relationship was investigated in wild and cultivated olive populations growing in Azad Jammu and Kashmir by using four primer combinations during Amplified Fragment Length Polymorphism (AFLP) analysis. Genetic relationships were displayed in a dendrogram based on Unweighted Pair Group Method (UPGMA) and Principal Component Analysis (PCA). Four clusters were clearly separating wild and cultivated olive populations from each other indicated that the Olea cuspidata (wild) which is an Afro-Asiatic species found particularly in this region and Olea europaea (cultivated) were divergent. The insightful difference between wild and cultivated populations and the close relationship among Olea europaea accessions had confirmed that the cultivated olive did not develop locally but were introduced from abroad, propagated by grafting on local wild olive. Moreover, analysis of cultivated olive showed that they are probably from same population with common ancestry.
\end{abstract}

Keywords: AFLP, genetic diversity, PCR, UPGMA, genetic similarity pattern, genotypes

\section{Introduction}

Olive cultivars and their wild relatives represent two botanical varieties of Olea europaea and var. sylvestris (Green, 2002). Both wild and cultivated olives, are diploid $(2 \mathrm{n}=2 \mathrm{x}=46)$, predominantly allogamous and distributed along the Mediterranean basin (Green, 2002). Wild olives reproduce sexually by wind pollination and their seeds are mainly dispersed by birds (Herrera, 1995). They are important components of the Mediterranean scrublands (Zohary and Hopf, 2000), even though the presence of isolated populations of oleasters has been reported in a Northern Euro-Siberian region of Spain (Vargas and Kadereit, 2001). Olive cultivars can be considered as varieties of unknown origin, currently propagated vegetatively by cutting or grafting. Most of them have a very restricted local area of diffusion (Besnard et al., 2001), while others have spread along wide agro-environments (Bronzini de Caraffa et al., 2002; Rotondi et al., 2003). Analysis of nuclear and cytoplasmic DNA polymorphisms in Mediterranean 
olive populations has shown that eastern olive populations differ greatly from those of the west Mediterranean (Besnard et al., 2001, 2002a; Lumaret et al., 2004), while the genetic diversity of cultivated populations shows a complex patchy pattern (Besnard et al., 2001b; Owen et al., 2005). The apparent contradiction regarding the distribution of olive and cultivated populations has fuelled the debate on the local origin of cultivated forms. Lumaret et al. (2004) proposed that populations of genuine wild olives are restricted to a few isolated areas of native Mediterranean forests, where pollen/stones may be distributed by wind/birds, while most other wild-looking forms of olive may include feral forms that escaped cultivation. Based on the frequency and distribution of polymorphisms, several authors have advanced the hypothesis of multilocal selection of cultivars from naturally cross-bred genotypes (Besnard et al., 2001; Rotondi et al., 2003). Others, highlighting the great genetic distance between populations of wild olives and cultivars, have suggested that large fractions of local sets of cultivars may have an allochthonous origin (Angiolillo et al., 1999; Bronzini de Caraffa et al., 2002).

The present study evaluated the organization of olive differentiation at a microscale regional level. The identification of genetically homogeneous groups of individuals has been reached by the implementation of structure software (Pritchard et al., 2000) and with amplified fragment length polymorphism (AFLP) dominant markers (Angiolillo et al., 1999; Sanz Cortes et al., 2003; Sensi et al., 2003; Owen et al., 2005) which has been shown to give results as accurate as microsatellites in such analyses (Evanno et al., 2005). It is important to note that in a few works, very restricted areas have been prospected (Baldoni et al., 2000; Bronzini de Caraffa et al., 2002), while most studies have dealt with wild and cultivated populations sampled from extended areas throughout the Mediterranean (Besnard et al., 2002b; Lumaret et al., 2004). Analyses at the microscale level are therefore expected to produce new elements for the general debate on olive domestication and to help understand how genetic diversity is partitioned among sets of cultivars (Manel et al., 2003). The long lifespan of the species has allowed 2000- to 3000-year-old olive trees to survive up to now in many Mediterranean regions (Lewington and Parker, 1999). In the actual application, the measurement of genetic variation among these populations is needed to guide the ongoing grafting of Olea europaea while ensuring that a substantial genetic diversity is preserved within the study area. For the Olea europaea nursery industry, this study can be useful to eliminate duplication of the clones and ensure diversity of the propagated clones for grafting on Olea cuspidata.

\section{Material and Methods}

\section{Collection of Plant Material}

The leaf samples of wild (Olea cuspidata Wall.) and cultivated olive (Olea europaea L.) were collected from twenty sites of Azad Jammu and Kashmir (Table 1). Leaf samples of wild and cultivated olive were collected from the young shoots of the tree canopy and placed individually in re-sealable plastic bags, labelled properly and then transported carefully to the laboratory in liquid nitrogen for further analysis. The leaves samples were kept in refrigerator at $-80{ }^{\circ} \mathrm{C}$ until required. The sampling locations were selected because they represent very different microclimatic conditions and also allowed the sampling of cultivated and wild olive ancestries at the same time (Fig. 1). The genetic characterization of wild and cultivated olive had never been reported before in this region. Azad Jammu and Kashmir have been considered as representatives of the 
most favourable conditions for the cultivation of olive where millions of trees of wild olive growing naturally (Ahmed et al., 2009).
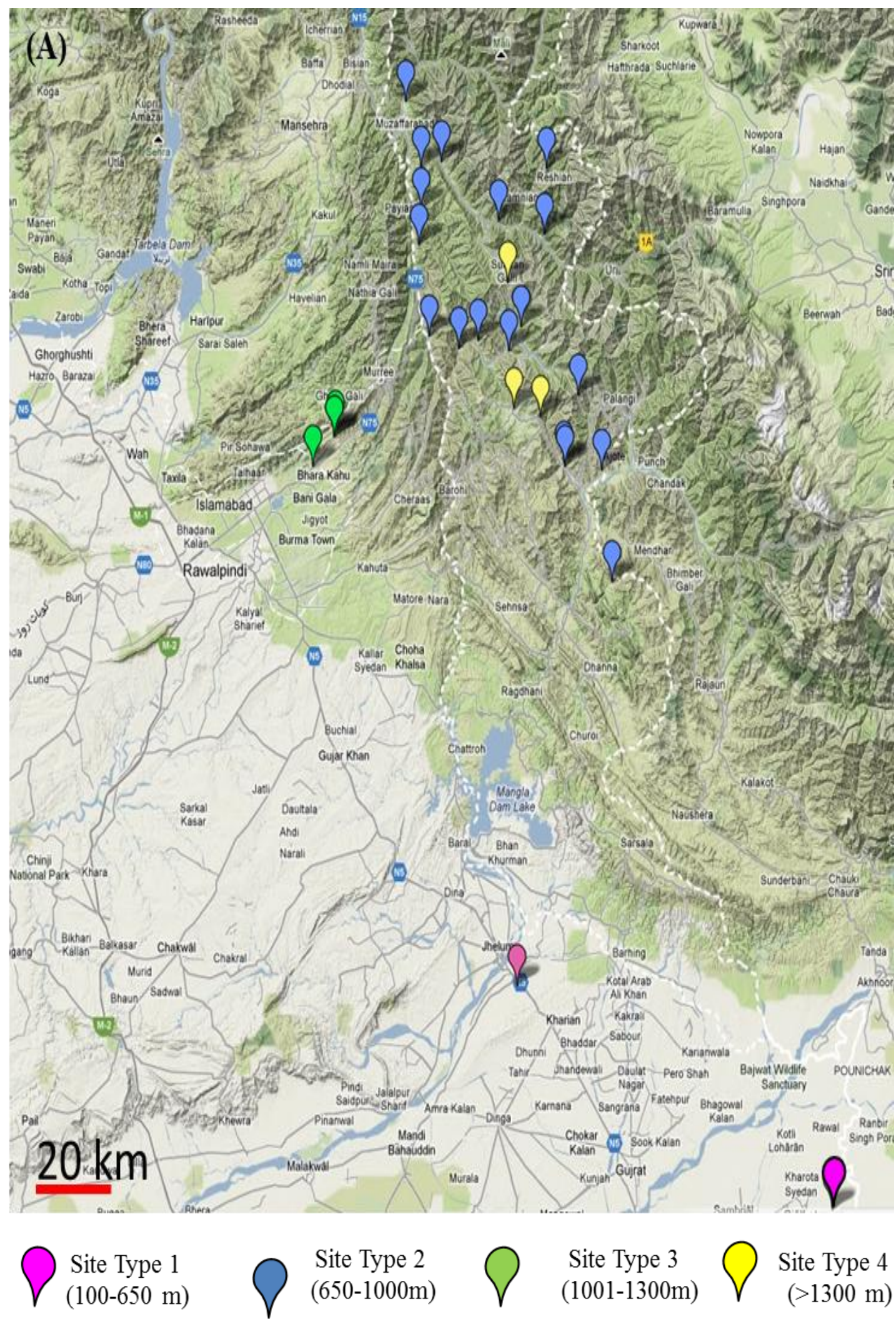

Figure 1. Map of wild and cultivated olive growing sites in Azad Jammu and Kashmir, Pakistan 
Table 1. List of sampling sites of wild and cultivated olive

\begin{tabular}{clcclc}
\hline Site No. & Localities & $\begin{array}{c}\text { Altitude } \\
(\mathbf{m})\end{array}$ & $\begin{array}{c}\text { Site } \\
\text { No. }\end{array}$ & Localities & $\begin{array}{c}\text { Altitude } \\
(\mathbf{m})\end{array}$ \\
\hline 1 & Bismeela & 830 & 11 & Chahla Muzaffarabd & 650 \\
2 & Barhan Barsala & 838 & 12 & Archid & 603 \\
3 & Satra Meel & 800 & 13 & Bhimber & 390 \\
4 & Salgran & 810 & 14 & Tetrinot & 854 \\
5 & Arja & 760 & 15 & Khaegala & 1587 \\
6 & Khapdar & 750 & 16 & Ghaziabad & 976 \\
7 & Mera Chaprian & 110 & 17 & Phagwati Hajira & 933 \\
8 & Nadhool & 896 & 18 & Kathae & 1089 \\
9 & Khunbandway & 750 & 19 & Khaegala & 1587 \\
10 & Bahawan & 696 & 20 & Kutla & 1000 \\
\end{tabular}

\section{DNA Extraction Procedure}

The DNA extraction was carried out from wild and cultivated olive samples by using cetyltrimethyl ammonium bromide (CTAB) extraction procedure as described by Futterer et al. (1995) and also by using Qiagen DNeasy ${ }^{\mathrm{TM}} 96$ Plant Kit (Shepherd et al., 2002). One or two leaves of sample were ground in liquid $\mathrm{N}_{2}$ by using mortar and pestle then added $400 \mu \mathrm{l}$ washing buffer, $100 \mu \mathrm{l}$ of 5 percent sarkosyl and $100 \mu \mathrm{l} 2 \mathrm{x}$ CTAB buffer in homogenized frozen tissues. Mixed carefully to form a paste then transfered it into $2 \mathrm{ml}$ microcentrifuge tubes and incubated at $65{ }^{\circ} \mathrm{C}$ for 15 minutes. After the incubation time, it was transferred a microcentrifuge tube to which was added $410 \mu \mathrm{l}$ phenol: chloroform: isoamylalcohol $(25: 24: 1)$ and mixed gently by inversion. This was then centrifuged at $14000 \mathrm{rpm}$ for six minutes. The supernatant was transferred to a new microcentrifuge tube and penol: chloroform: isoamylalcohol $(410 \mu \mathrm{l})$ was again added following by microcentrifugation for ten minutes at $13000 \mathrm{rpm}$. The upper layer was transferred to a new tube and 2.5 volume of ice cold 95 percent ethanol was added and incubated at room temperature for 2.5 hours. This was then centrifuged at $14000 \mathrm{rpm}$ for 30 minutes to precipitate the DNA. The pellet was twice washed with 70 percent ethanol and then the pellet was allowed to dry. Solubilized the pellet in $100 \mu \mathrm{TE}$ solution containing $100 \mu \mathrm{g}$ RNase, incubated at $37{ }^{\circ} \mathrm{C}$ for 30 minutes and then stored it in refrigerator for further studies. DNA quality was checked by electrophoresis in one percent agarose gel. For this purpose PCR amplification was carried out by using DNA Barcode primer (Invitrogen by life technologies ${ }^{\mathrm{TM}}$ ) with following sequence:

Primer-1, rbcLaF (5' to 3'); TGT AAA ACG ACG GCC AGT ATG TAC CCA CAA ACA GAG ACT AAA GC Primer-2, rbcLaR (5' to $3^{\prime}$ ); CAG GAA ACA GCT ATG ACG TAA AAT CAA GTC CAC CRC G. 


\section{Amplified Fragment Length Polymorphism (AFLP) Protocol}

Amplified Fragment Length Polymorphism (AFLP) is a PCR based tool, recently used in DNA fingerprinting was developed in the early 1990s by Keygene. Amplified Fragment Length Polymorphism (AFLP) analysis was carried out by using the previously described method of Vos et al. (1995) and Angiolillo et al. (1999). Four selective primer combinations i.e. ACG-CCT, ACG-CGT, ACG-CTA, ATC-CCT were used for the genetic characterization of wild and cultivated olive.

Four steps involved in AFLP reaction i.e. digestion, ligation, pre-selective amplification and selective amplification. Genomic DNA (500 ng) processed with EcoRI and MseI restriction enzymes and adapters EcoRI and MseI ligation were done in a final volume of $11 \mu \mathrm{l}$. The reaction included 1x T4 ligase buffer $(50 \mathrm{mM}$ Tris- $\mathrm{HCl}$ (pH 7.5), $10 \mathrm{mM} \mathrm{MgCl} 2,10 \mathrm{mM}$ dithiothreitol, $1 \mathrm{mM}$ ATP) (New England Biolabs), 8 Ipswich, MA), $0.05 \mathrm{M} \mathrm{NaCl}, 0.045 \mathrm{mg} / \mathrm{ml}$ BSA, $1 \mu \mathrm{M}$ EcoRI adapter, $5 \mu \mathrm{M} \mathrm{MseI}$ adapter, 5U EcoRI (New England Biolabs), 5U MseI (New England Biolabs) and 1U T4 DNA ligase (New England Biolabs). All these regents were mixed gently and then incubated for three hours at $37^{\circ} \mathrm{C}$. After restriction and ligation, the reaction mixture was diluted 10-fold with $0.1 \times$ TE buffer (10 mM Tris- $\mathrm{HCl}$ ( $\mathrm{pH} 8.0), 0.1 \mathrm{mM}$ EDTA).

Pre-selective amplification was carried out in a final volume of $13 \mu 1$ consisting of $1 \mathrm{x}$ PCR buffer (100mM Tris-HCl (pH 8.3), 500mM KCl), $2.0 \mathrm{mM} \mathrm{MgCl}_{2}, 0.2 \mathrm{mM}$ dNTP, $10 \mu \mathrm{M} E c o \mathrm{RI}+\mathrm{A}$ primer, $10 \mu \mathrm{M} M s e \mathrm{I}+\mathrm{C}$ primer and $3 \mu \mathrm{L}$ of diluted restriction-ligation product. PCR was carried out in a MyCycler thermal cycler (Bio-Rad Laboratories, Hercules, CA) programmed at $72{ }^{\circ} \mathrm{C}$ for 2 min followed by 30 cycles of $94{ }^{\circ} \mathrm{C}$ for 30 sec, $56^{\circ} \mathrm{C}$ for $30 \mathrm{sec}, 72{ }^{\circ} \mathrm{C}$ for $2 \mathrm{~min}, 60^{\circ} \mathrm{C}$ for $10 \mathrm{~min}$ and finally hold at 25 or $4{ }^{\circ} \mathrm{C}$.

For selective amplification, the pre-selective amplification PCR products were diluted 10-fold in $0.1 \mathrm{x}$ TE buffer and used as template for selective amplification. $8 \mu \mathrm{l}$ reaction volume containing 1x PCR buffer (100 mM Tris- $\mathrm{HCl}(\mathrm{pH} 8.3), 500 \mathrm{mM} \mathrm{KCl})$, $2.0 \mathrm{mM} \mathrm{MgCl} 2,0.2 \mathrm{mM}$ dNTPs, $0.625 \mu \mathrm{M}$ EcoRI primer (E+3), $0.625 \mu \mathrm{M} \mathrm{MseI}$ primer $(\mathrm{M}+3)$, fluorescent dye labeled that can be detected by the ABI 3100 DNA fragment Analyzer, 0.2 Units of JumpStart Taq DNA polymerase (Sigma) and $2 \mu \mathrm{l}$ of diluted preselective amplification product were used for selective amplification.

The PCR amplification was carried out with an initial denaturation step of $94{ }^{\circ} \mathrm{C}$ for $2 \mathrm{~min}$, followed by the first cycle of $94{ }^{\circ} \mathrm{C}$ for $30 \mathrm{sec}, 65^{\circ} \mathrm{C}$ for $30 \mathrm{sec}, 72{ }^{\circ} \mathrm{C}$ for $2 \mathrm{~min}$ and $1{ }^{\circ} \mathrm{C}$ in annealing temperature in each of the next nine cycles. This was followed by 25 cycles of $94{ }^{\circ} \mathrm{C}$ for $30 \mathrm{sec}, 56{ }^{\circ} \mathrm{C}$ for $30 \mathrm{sec}$, and $72{ }^{\circ} \mathrm{C}$ for $10 \mathrm{~min}$. The reactions were hold at $4{ }^{\circ} \mathrm{C}$ for $30 \mathrm{~min}$ before electrophoresis. PCR products were diluted 50 -fold with sample loading solution (Beckman-Coulter Inc., Fullerton, CA) and $1.5 \mu$ of diluted reaction products were added to $40 \mu \mathrm{l}$ of sample loading solution (BeckmanCoulter Inc., Fullerton, CA). DNA size standard 600 (Beckman-Coulter Inc., Fullerton, CA) was also added to each sample. The samples were electrophoresed and detected using a Beckman-Coulter CEQ 8800 Genetic Analysis System (Beckman-Coulter, Fullerton, CA). The Frag-4 module of CEQ was used to size all the fragments using internal DNA size standard.

\section{Data Analysis}

All AFLP fragments were scored as binary data (1, peak present; 0, peak absent) along with their sizes. The binary scores were manually compared with the electropherograms to confirm presence or absence of peaks. A cluster analysis was 
performed using unweighted pair group method (UPGMA) based on the Dice index (Nei and Li, 1979). This analysis was conducted using the Free Tree software package (Hampl et al., 2001). Principal component analysis (PCA) was used as a data reduction tool to summarise the information from AFLP data so that the influence of noise and outliers on the clustering results was reduced (Ruiz et al., 1997).

\section{Results and Discussion}

A total 40 leaf samples of wild (Olea cuspidata Wall.) and cultivated olive (Olea europaea L.), collected from twenty localities of Azad Jammu and Kashmir were characterized by using AFLPs techniques as describe by Vos et al. (1995) and Angiolillo et al. (1999). The sampling locations were selected as they represent varied types of micro-climatic conditions and they may also encompass different wild olive ancestries. The genetic characterization of wild and cultivated olive has not been reported before in this region and cultivation of olive is restricted to few areas, made possible by the use of selected and well established local varieties. Azad Jammu and Kashmir have been chosen as representatives of the most favourable conditions for the cultivation of olive where millions of trees of wild olive growing naturally (Ahmed et al., 2009; Panhwar, 2005). Four primer combinations were selected for the present study based on the ones that gave the most variation i.e. ACG-CCT, ACG-CGT, ACG-CTA, ATC-CCT. The number of noticeable fragments by each AFLP primer pair was variable. The polymorphisms percentage ranged from 42 to 58 percent, depending on the primer combinations. The two selective primer pairings were used. (1) ACGCCT paired with ACGCGT and (2) ACGCTA paired with ATCCCT. Selective amplification of pair 1 yielded 78 fragments of which $45(58 \%)$ were variable and pair 2 yielded 93 fragments of which $39(42 \%)$ were variable. This study was concatenated the runs and ran the analysis on 171 alleles of which 94 (55\%) were polymorphic.

AFLP markers have previously been used in the study of relationship and genetic diversity of olive. The 65 olive samples were analysed by Owen et al. (2005) that include some important cultivars from western Mediterranean region, Greece, Turkey and Middle East. Their study resulted 119 polymorphic fragments by using five AFLP primer combinations, which revealed 41 percent polymorphism. The collective data sets produced by just two primer pairs were adequate to differentiate all 65 genotypes. The 12 accessions of cultivated olive from Italy were characterized by Sensi et al. (2003) using six pairs AFLP markers. Their results depicted 274 fragments of which over all 164 loci $(59 \%)$ were polymorphic. The polymorphic fragments detected by each primer pair were variable from 13 (for primer pair 3) to 40 (for primer pair 1). The primer combinations showed difference in their ability to detect polymorphism within populations. Kamoun et al. (2006) characterized 29 samples of Tunisian olive by using 9 AFLP primer combinations. Their study showed that these nine primers produced 410 fragments, among which 172 fragments were polymorphic. The results verified a high degree of polymorphism in the olive samples with an average of 39 percent. In the present investigation over all polymorphism ratio observed among 40 olive samples of Azad Jammu and Kashmir is comparable with these studies. The smaller number of fragments per primer combination detected in the present study as compared to previous investigations may be due to smaller number of primers used.

The dendrogram produced on the basis of AFLP and UPGMA cluster analysis were shown in Figure 2. The dendrogram revealed 4 distinct groups which could be seen in 
two main branches of dendrogram. These two branches clearly separated wild and cultivated olive from each other. Dendrogram revealed that group I comprised of 10 samples of cultivated olive collected from Satra Meel, Archid, Arja, Bhimber, Bismeela, Salgran, Tetrinot, Kathae, Chahla and Khunbandway. All the samples in this group were cultivar except samples Arja and Bhimber. These two samples were the two landrace accessions from Azad Kashmir and were separated from the subclusters as singleton. Similarly group II comprises of 10 accessions of cultivated olive collected from Barsala, Nadool, Ghaziabad, Bahanwan, Khaegala, Merachaprian, Khaegala, Khapdar, Kutla and Phagwati. All the samples in this group were also cultivar except those from Kutla and Phagwati. These two samples were the two landrace accessions from Azad Kashmir and were separated from the subclusters as singleton. All these samples were collected from different localities at different altitude of study area (Table 1). All the 20 samples of cultivated olive clustered in groups I and II with some subgroups due to genetic relationship with each other. Recently propagation of cultivated olive (Olea europaea L.) has been started in Azad Kashmir vegetatively by top working or grafting on wild olive. Most of them may have a common ancestory and may also have limited area of diffusion. This observation is in agreement with the previous study of Besnard et al. (2001).

Group III consisted of five accession of wild olive collected from Tetrinot, Ghaziabad, Arja, Bhimber and Merachaprian. Olea cuspidata samples of Bhimber and Merachaprian represented as singleton in main cluster. Group IV comprises of 14 accessions sampled from different localities of Azad Kashmir i.e. Kathae, Archid, Phagwati, Khaegala, Chahla, Salgran, Bahawan, Khunbandway, Barsala, Bismeela, Nadool, Khapdar, Kutla and Satra Meel. This cluster comprises of 4 subclusters. All the samples in this group were also cultivar except Olea cuspidata collected from Satra Meel, Nadool, and Bahawan. These three samples were the three landrace accessions from Azad Jammu and Kashmir and were separated from the subclusters as singleton. These samples were collected from different localities at different (390-1587 m) altitude of Azad Jammu and Kashmir. Wild olive clustered in groups I and II with subgroups might be due to genetic relationship with each other in the cluster. Wild olive showed more variation as compared to cultivated olive.

According to Kamoun et al. (2006) the AFLP marker system was able to separate closely related olive accessions. Present results are also in line with this study. Moreover, Angiolillo et al. (1999), Belaj et al. (2003) suggested that AFLP marker system is suitable for the genetic characterization of crop plants.

According to Lumaret et al. (2004) the wild and cultivated olive analysis based on allozyme proposed similar allelic distributions in both populations and higher heterozygosity in wild olive than in cultivated population. The studies of Vargas and Kadereit (2001) based on ISSR revealed that cultivated olives are nested within wild populations indicating that wild and domesticated olives exchanged genetic material through hybridization.

The present results based on AFLPs analysis depicted a clear representation about the relationship of both species. The results demonstrated that cultivated olive in this region was domesticated without the contribution of wild olive. For instance, this study is consistent with the explanation that the cultivated olive shows an example of the genetic dissimilarity in wild olive populations that exists today in this region.

A dendrogram exhibited the occurrence of four clusters suggestively different from one another. Each cluster and subcluster contained at least 1 or more samples from the same population. The overall trend assumed the derivation of cultivated population from 
the wild population. The scattering of these groups within the population indicates that wild population spread might be by outcrossing as mating system of crop plants seems to play an important role in genetic diversity (Mekuria et al., 2002).

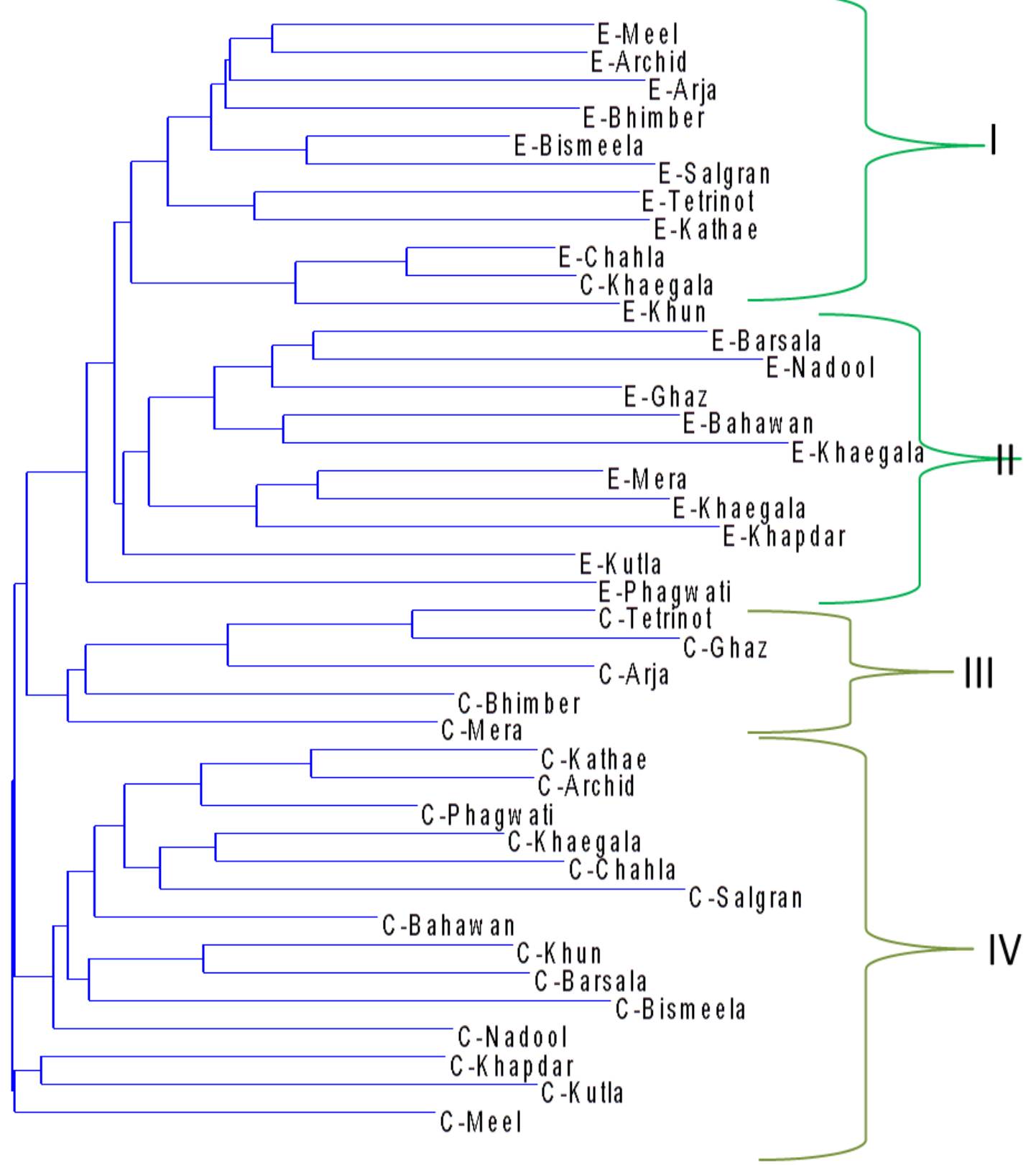

Figure 2. Dendrogram revealing genetic variation between wild and cultivated olive of Azad Jammu and Kashmir based on AFLP and cluster analysis (UPGMA).

The certain degree of relationship of cultivated olive to wild olive of Azad Jammu and Kashmir is perhaps due to the propagation system in this area, usually carried out by grafting onto wild olive plants, taking into account that old trees of wild olive while ten to fifteen year old tree of cultivated olive were considered in present work. The current results are in harmony with the previous study of Lumaret and Ouazzani (2001). 
Furthermore, these results are also in agreement with the previous work of Baldoni et al. (2006). Their investigations revealed that the genetic variation observed through AFLP markers exhibited a clear difference of wild olive from cultivated landraces. The previous investigations of Angiolillo et al. (1999) and Caraffa et al. (2002) on cultivated populations are also in congruence with the present study. The samples of both species that represented as singleton in the dendrogram probably due to mutation within population as these samples were collected from distinct climatic conditions. Indeed, they were grouped in to distinguished subclusters. This is in line with the study of Albertini et al. (2011). Their results suggested that climatic conditions responsible for mutation in single population along with both sexual and vegetative propagation played a role in the evolution of olive. Due to this reason the samples may grouped in two discriminated subclusters belonging to the same single and very well maintained population. Genetic diversity is considerably higher in the Olea cuspidata as compared to the Olea europaea population, supporting the general notion that wild olive $(O$. cuspidata) are authentic, eminent earlier whereas $O$. europaea evolved through hybridization (Breton et al., 2006).

\section{Principal Component Analysis}

The Principal component analysis (PCA) tool was also used as to analyse the AFLP data. PCA reduces data to principal components which summarizes variation within a given data set. This decreases the number of descriptors responsible for the highest percentage of total variance of the experimental data. It allows the relationship between variables and observations to be studied, as well as recognizing the data structure. Falcinelli et al. (1988) and Chozin (2007) showed multivariate analyses to be a valid system to deal with germplasm collections and evaluation. Similarly, Dasgupta and Das (1984) and Chozin (2007) considered multivariate analysis best for choosing parents for hybridization. PCA is used to reveal the pattern of character variation among individual accession in a population (Chozin, 2007).

PCA bi-plots provided an indication of the similarities and variation between the genetic diversity among different accessions of the same genotype and interrelationships between both genotypes. The PC1 and PC2 cumulatively explained 32.11 percent of the total variation among 40 samples of olives (Fig. 3a, b). The PC1 elucidated 17.61 percent variation, followed by 14.50 percent for the PC2. Projection of both genotypes on a two-dimensional plane, based on the first two PCs, partially confirmed the results of dendrogram. The accessions from the UPGMA clusters similarly inclined to form their own groups in the PCA, however usually overlapping. Samples which overlapped in the PC axes revealed similarity in their genetic relationship. Both wild and cultivated olive accessions remain scattered in all quadrants, showing large genetic variability particularly $O$. cuspidata culustered on left of ordination plot while O. europaea grouped on right (Fig. 3a,b).

In the top two quadrants of the projection, a more compact group of Olea cuspidata was comprised of samples collected from different geographical localities. These localities were Salgran, Bismeela. Kathae, Phagwati, Archid, Chahla and Khaegala, almost overlapping in the group while Olea europaea accessions also projected compact group which include samples collected from Barsala, Nadool, Bahawan, Khaegala, Ghaziabad, Khapdar, Tetrinot, Kutla, Khaegala and Merachaprian. Meanwhile in the lower two quadrants of the projection, a loose group of Olea cuspidata was comprised of Bahawan, Nadool, Khunbandway, Barsala, Khapdar, Satra Meel Kutla, Bhimber, 
Merachaprian, Arja, Tetrinot and Ghaziabad localities, depicting clear variation and high polymorphism within species while Olea europaea accessions projected comparatively compact group with overlapping trends which contains samples collected from 10 localities i.e. Kathae, Bhimber, Khaegala, Archid, Satra Meel, Phagwati, Khunbandway, Bismeela, Arja and Salgran. Overlapping groups of both genotypes from almost all UPGMA clusters comprise the top to lower quadrants of the projection. They represented variation within and between both genotypes. PC1 and PC2 elucidated greater variation in Olea cuspidata whereas less variation in Olea europaea of Azad Jammu and Kashmir. These results are in agreement with the previous studies of Chatfied and Collin (1980). Likewise, Hair et al. (1998) also suggested the similar projections in their investigation.

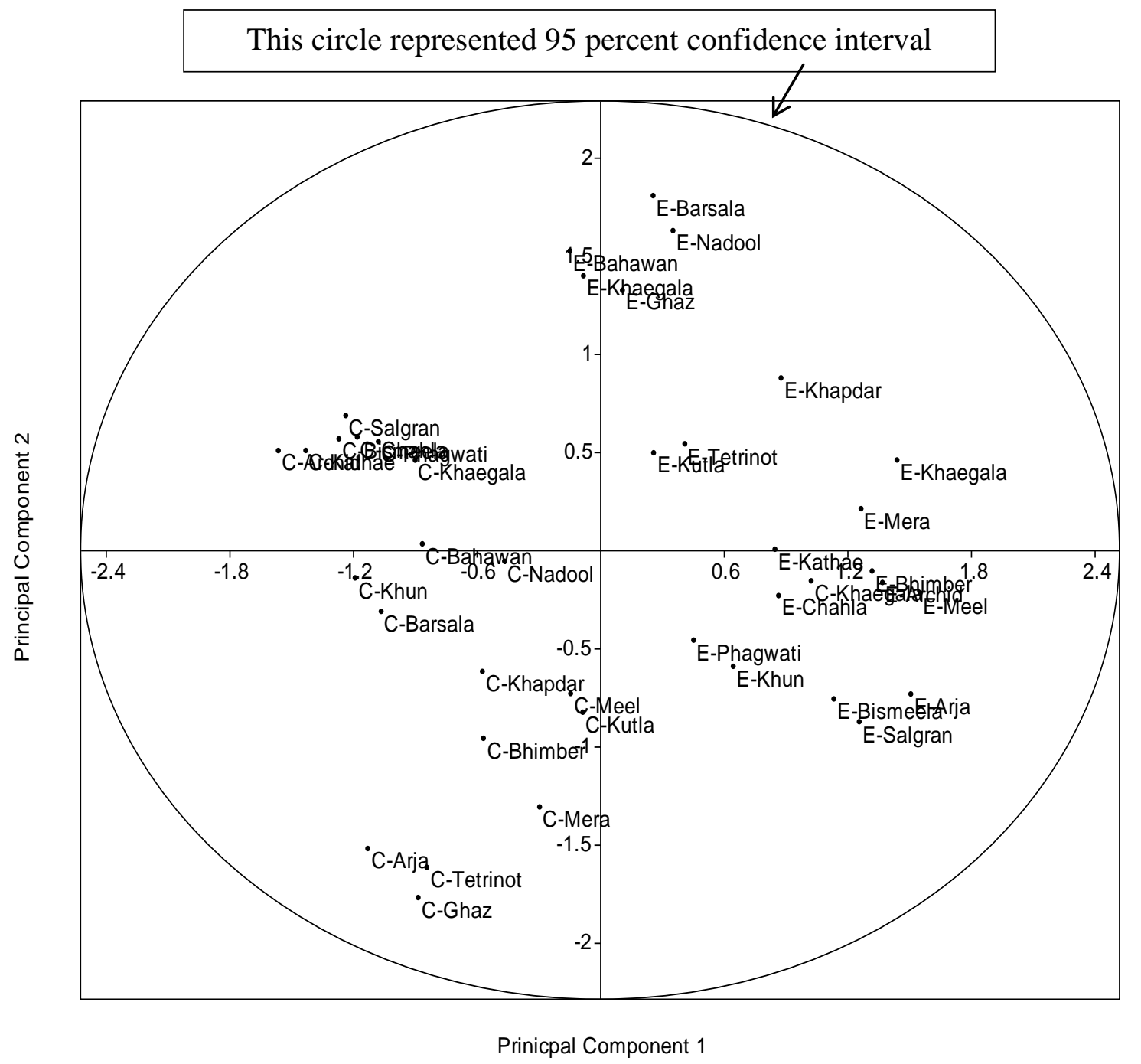

Figure 3a. Principal component analysis (PCA) describing the overall variation between wild and cultivated olive by using AFLP analysis data. 


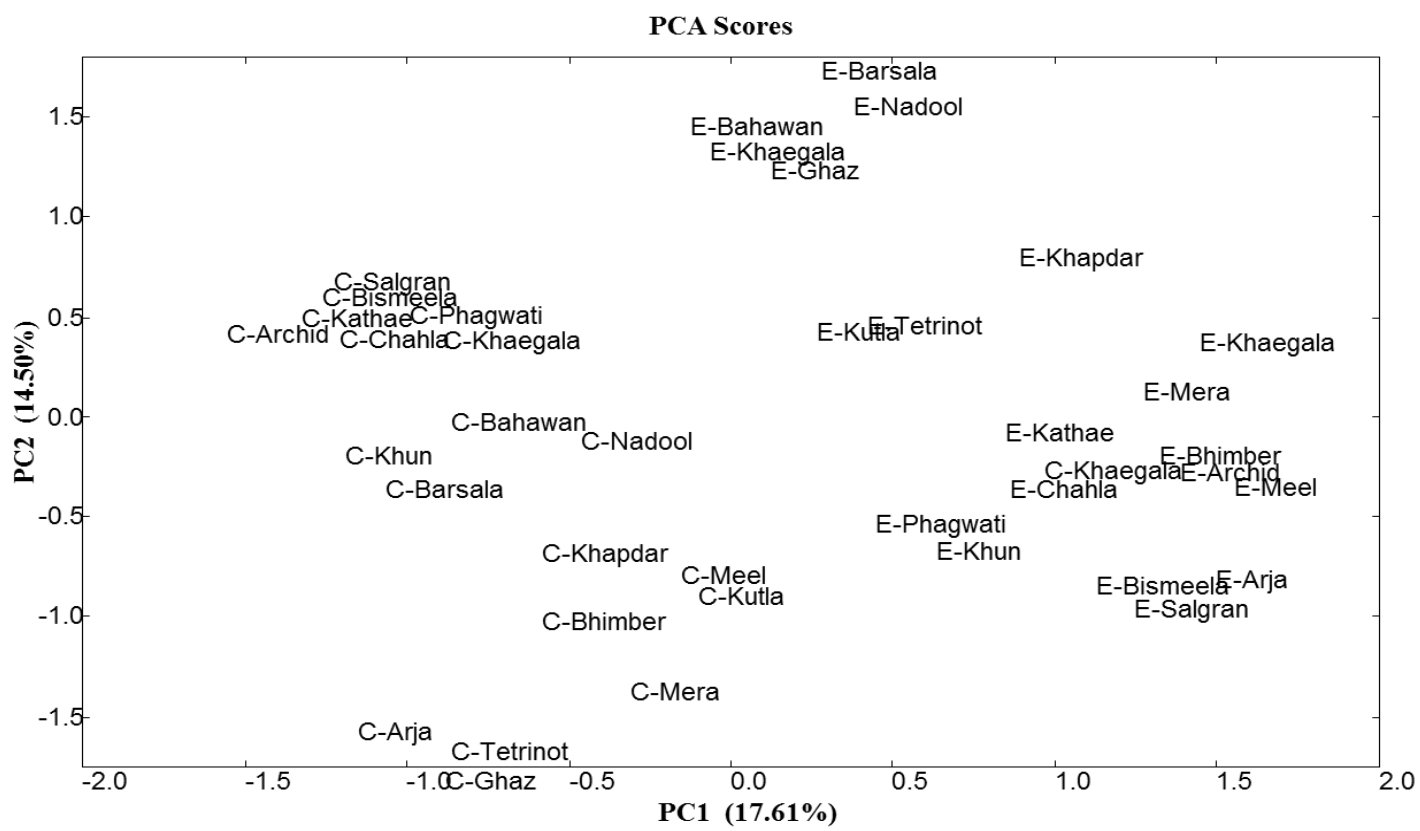

Figure 3b. Two-dimensional projection of olive accessions along the first two principal components axes

The AFLP results obtained led to the assumption that the Olea cuspidata (wild) and Olea europaea (cultivated) were divergent. The clear difference between wild and cultivated populations and the close relationship among Olea europaea accessions have confirmed that the cultivated olive did not develop locally but were introduced from abroad, propagated by grafting on local wild olive. The analysis of cultivated olive samples collected from different localities of Azad Jammu and Kashmir having different microclimatic conditions along the altitudinal gradient suggested that they are probably from same population with common ancestry.

\section{Conclusion}

The knowledge of the genetic diversity is essential for their survival, ecology and development of appropriate germplasm for a diverse set of environments. The information provided in this study is useful for genetic improvement of olive because these molecular evidences were describing important differences between both species in a given area and given population.

Thus, this molecular genetic analysis provides new insights regarding the extent of diversity of individuals within and between populations. The present study determined the relatedness and obtained information on population structure and genetic diversity of wild and cultivated olive using AFLP. The AFLP analysis appeared to be efficient in verifying its variety status. In the actual application, the measurement of genetic differences among these populations is needed to guide the on-going grafting of Olea europaea while ensuring that a substantial genetic diversity is preserved within the study areas. For the Olea europaea nursery industry, this study can be useful to eliminate duplication of the clones and ensure the diversity of the propagated clones for grafting on Olea cuspidata. 


\section{REFERENCES}

[1] Ahmed, M., Khan, N., Wahab, M., Hamza, S., Sidiqui, M. F., Nazim, K., Khan, M. U. (2009): Vegetation structure of Olea ferruginea Royle forests of lower Dir District of Pakistan. - Pak. J. Bot. 41(6): 2683-2695.

[2] Albertini, E, Torricelli, R., Bitocchi, E., Raggi, L., Marconi, G., Pollastri, L., Minco, G. D., Battistini, A., Papa, R., Veronesi, F. (2011): Structure of genetic diversity in Olea europaea L. cultivars from central Italy. - Mol. Breed. 27:533-547.

[3] Angiolillo, A., Mencuccini, M., Baldoni, L. (1999): Olive genetic diversity assessed using amplified fragment length polymorphisms. - Theor. App. Gen. 98: 411-421.

[4] Baldoni, L., Pellegrini, M., Mencuccini, M., Angiolillo, A., Mulas, M. (2000): Genetic relationships among cultivated and wild olives revealed by AFLP markers. - Acta Hortic. 521: 275-284.

[5] Baldoni, L., Tosti, N., Ricciolini, C., Belaj, A., Arcioni, S., Pannelli, G., Germana, M. A., Mulas, M., Porceddu, A. (2006): Genetic structure of wild and cultivated olives in the central Mediterranean basin. - Ann. Bot. 98:935-942.

[6] Belaj, A., Satovic, Z., Cipriani, G., Baldoni, L. (2003): Comparative study of the discriminating capacity of RAPD, AFLP, and SSR markers and of their effectiveness in establishing genetic relationships in olive. - Theor. App. Gen. 107: 736-744.

[7] Besnard, G., Baradat, P., Berville, A. (2001): Genetic relationships in the olive (Olea europaea L.) reflect multilocal selection of cultivars. - Theor. App. Gen. 102:251-258.

[8] Breton, C., Tersac, M., Berville, A. (2006): Genetic diversity and gene flow between the wild olive (oleaster, Olea europaea L.) and the olive: several Plio-Pleistocene refuge zones in the Mediterranean basin suggested by simple sequence repeats analysis. - J. Biogeo. 33:1916-1928.

[9] Caraffa, B. V., Maury, J., Gambotti, C., Breton, C., Berville, A., Giannettini, J. (2002): Mitochondrial DNA variation and RAPD mark oleasters, olive and feral olive from Western and Eastern Mediterranean. - Theor. App. Gen. 104: 1209-1216.

[10] Chatfield, C., Collin, A. J. (1980): Introduction to multivariate analysis. - Chapman and Hall in Association with Methuen, Inc., 733 Third Avenue, New York NY10017, USA.

[11] Chozin, M. (2007): Characterization of sorghum accessions and choice of parents for hybridization. - J. A. A. E. Khus. 2:227-232.

[12] Dasgupta, T., Das, P. K. (1984): Multivariate analysis and selection of parents for hybridization in blackgram. - Phil. Agri. 57: 86-92.

[13] Evanno, G., Regnaut, S., Goudet, J. (2005): Detecting the number of clusters of individuals using the software STRUCTURE: a simulation study. - Mol. Ecol. 14: 26112620.

[14] Falcinelli, M., Veronesi, F., Lorenzetti, S. (1988): Evaluation of an Italian germplasm collection of Lolium perenne L. through a multivariate approach. - Proceedings of the Eucarpia Fodder Crops Section Meeting. Lusignan, France.: 24.

[15] Futterer, J., Gisel, A., Iglesias, V., Kloti, A. (1995): Standard Molecular Techniques for the Analysis of Transgenic Plants. - In: Potrykus, I., Spangenberg, G. (eds.) Gene Transfer to Plants. Springer-Verlag, New York, pp. 215-218.

[16] Green, P. S. (2002): Arevision of Olea L. (Oleaceae). - Kew Bull. 57: 91-140.

[17] Hair, J. F., Andrson, J. R., Tatham, R. E., Black, W. C. (1998): Multivariate data analysis, 5th ed. - Prentice-Hall international, Inc., London.

[18] Hampl, V., Pavlicek, A., Flegr, J. (2001): Construction and bootstrap analysis of DNA fingerprinting-based phylogenetic trees with the freeware program FreeTree: application to trichomonad parasites. - I. J. Syst. Evol. Micr. 51: 731-735.

[19] Herrera, C. (1995): Plant-vertebrate seed dispersal systems in the Mediterranean: ecological, evolutionary, and historical determinants. - Annu. Rev. Ecol. Evol. Syst. 26: 705-727. 
[20] Kamoun,G. N., Mahmoud, F., Rebai, A., Gargouri, A. (2006): Genetic diversity of Tunisian Olive Tree (Olea europaea L.) cultivars assessed by AFLP markers. - Gen. Res. C. Evol. 53: 265-275.

[21] Lewington, A., Parker, E. (1999): Ancient trees. Trees that live for a thousand years. London: Collins \& Brown.

[22] Lumaret, R., Ouazzani, N. (2001): Ancient wild olives in Mediterranean forests. - Nat. 413:700.

[23] Lumaret, R., Ouazzani, N., Michaud, H., Vivier, G., Deguilloux, M. F., Giusto, F. D. (2004): Allozyme variation of oleaster populations (wild olive tree) in the Mediterranean Basin. - Heredity 92: 343-351.

[24] Manel, S., Schwartz, M. K., Luikart, G., Taberlet, P. (2003): Landscape genetics: combining landscape ecology and population genetics. - Trends Ecol. Evolut. 18: 189197.

[25] Mekuria, G. T., Collins, G., Sedgley, M. (2002): Genetic diversity within an isolated olive (Olea europaea L.) population in relation to feral spread. - Sci. Hort. 94:91-105.

[26] Nei, M., Li, W. H. (1979): Mathematical-model for studying genetic-variation in terms of restriction endonucleases. - P. Nat. A. Sci. USA 76: 5269-5273.

[27] Owen, C. A., Bita, E. C., Banilas, G., Hajjar, S. E. (2005): AFLP reveals structural details of genetic diversity within cultivated olive germplasm from the Eastern Mediterranean. Theor. App. Gen. 110: 1169-1176.

[28] Panhwar, F. (2005): Cultural practice of olive growing and its future. - Digit. Gmbh. Germany :1-7.

[29] Pritchard, J. K., Stephens, M., Donnelly, P. (2000): Inference of population structure using multilocus genotype data. - Genetics 155: 945-959.

[30] Rotondi, A., Magli, M., Ricciolini, C., Baldoni, L. (2003): Morphological and molecular analyses for the characterization of a group of Italian olive cultivars. - Euphytica 132: 129-137.

[31] Ruiz, M., Varela, F., Carillo, J. M. (1997): Analysis of the discriminating power of agromorphological and biochemical descriptors in a sample of Spanish collection barely (Hordeum vulgare L.). - Gen. Res. C. Evol. 44: 247-255.

[32] Sanz-Cortes, F., Parfitt, D. E., Romero, C., Struss, D., Llacer, G., Badenes, M. L. (2003): Intraspecific olive diversity assessed with AFLP. - Plant Breeding 122: 173-177.

[33] Sensi, E., Vignani, R., Scali, M., Masi, E. (2003): DNA fingerprinting and genetic relatedness among cultivated varieties of Olea europaea L. estimated by AFLP analysis. Sci. Hort. 97: 379-388.

[34] Shepherd, M., Cross, M. J., Stokoe, R. L., Scott, L. J., Jones, M. E. (2002): Highthroughput DNA extraction from forest trees. - P. Mol. Biol. Rep. 20 (4): 425.

[35] Vargas, P., Kadereit, J. W. (2001): Molecular fingerprinting evidence (ISSR, inter-simple sequence repeats) for a wild status of Olea europaea L. (Oleaceae) in the Eurosiberian North of the Iberian Peninsula. - Flora 196:142-152.

[36] Vos, P., Hogers, R., Bleeker, M., Reijans, M., Lee, T. V., Hornes, M., Frijters, A., Pot, J., Kuiper, M., Zabeau, M. (1995): AFLP: A new technique for DNA fingerprinting. - N. A. Res. 23: 4407-4414.

[37] Zohary, D., Hopf, M. (2000): Domestication of plants in the Old World: the origin and spread of cultivated plants in West Asia, Europe, and the Nile Valley. - New York: Oxford University Press. 